\title{
Deus está morto. Viva o autômato!
}

\author{
God is dead. Long live the automaton!
}

\section{Dios ha muerto. iViva el autómata!}

\section{Amadeu de Oliveira Weinmann}

Universidade Federal do Rio Grande do Sul - UFRGS, Porto Alegre, Rio Grande do Sul, Brasil

\section{Roberto Henrique Amorim de Medeiros}

Universidade Federal do Rio Grande do Sul - UFRGS, Porto Alegre, Rio Grande do Sul, Brasil

\section{Gustavo Caetano de Mattos Mano}

Universidade Federal do Rio Grande do Sul - UFRGS, Porto Alegre, Rio Grande do Sul, Brasil

\begin{abstract}
RESUMO
O artigo propõe-se a pensar algo do pathos da Modernidade - a paixão pelo autômato -, à luz do conceito nietzschiano Morte de Deus. Nesse sentido, toma como matéria de análise dois clássicos do cinema de ficção científica: 2001: uma odisseia no espaço, de Stanley Kubrick, e Blade runner, de Ridley Scott. Se a paixão pelo autômato consiste em uma forma do sujeito moderno denegar a finitude, nos filmes em debate tal condição é elaborada de um modo muito singular. 2001 e Blade runner oferecem ao espectador a possibilidade de resistir à assunção dessa inclinação da subjetividade moderna. Em 2001, o autômato é demasiado humano e uma narrativa trágica promove outro modo de enfrentar a finitude. Em Blade runner, o autômato é o portador das angústias fundamentais do sujeito moderno origem e finitude - e a identificação a ele permite ao espectador ir além do homem.
\end{abstract}

Palavras-chave: psicanálise, cinema, morte de Deus, finitude, autômato.

\begin{abstract}
The article proposes to address an issue from Modernity pathos - the passion for the automaton -, in the light of Nietzschian Death of God concept. In this sense, it analyses two science fiction classic movies: 2001: a space odyssey, by Stanley Kubrick, and Blade runner, by Ridley Scott. If passion for the automaton consists in a form of the modern subject to deny finitude, in the films here discussed such condition is elaborated in a very peculiar way. 2001 and Blade runner offer the spectator the possibility of resisting the assumption of such tendency of modern subjectivity. In 2001, the automaton is too human and a tragic narrative promotes another way of tackling finitude. In Blade runner, the automaton is the bearer of
\end{abstract}


fundamental anguishes of the modern subject - origin and finitude - and by identifying with him the viewer is allowed to go beyond man.

Keywords: psychoanalysis, cinema, death of God, finitude, automaton.

\section{RESUMEN}

El artículo se propone a pensar algo respecto al pathos de la Modernidad - la pasión por lo autómata - bajo el concepto de Nietzsche Muerte de Dios. En este sentido, el análisis toma como materia dos clásicos del cine de ciencia ficción: 2001: una odisea del espacio, de Stanley Kubrick, y Blade runner, de Ridley Scott. Si la pasión por lo autómata consiste en una forma del sujeto moderno denegar la finitud, en esas películas tal condición es elaborada de una manera muy singular. 2001 y Blade runner ofrecen al espectador la posibilidad de resistir a la asunción de tal inclinación de la subjetividad moderna. En 2001, el autómata es demasiado humano y una narrativa trágica promueve otro modo de enfrentar la finitud. En Blade runner, el autómata es el portador de las angustias fundamentales del sujeto moderno - de origen y finitud - y la identificación a él le permite al espectador ir más allá del hombre.

Palabras clave: psicoanálisis, cine, muerte de Dios, finitud, autómata.

\section{Introdução}

Paixão pelo autômato é um conceito que os autores vêm lapidando, a partir de um amplo corpus de filmes de ficção científica, com o intuito de indicar algo do pathos da Modernidade. Neste artigo, a partir da perspectiva da psicanálise, articulamos a paixão pelo autômato e o conceito nietzschiano Morte de Deus. Tal enlace é decorrente do trabalho de análise de um clássico da ficção científica: 2001: uma odisseia no espaço (1968), de Stanley Kubrick. A articulação entre a paixão pelo autômato e a Morte de Deus permeia o texto fílmico de 2001 de um modo surpreendente: o filme de Kubrick elabora essa condição dos sujeitos modernos de uma forma que permite ultrapassá-la. Se, como postulamos, a paixão pelo autômato consiste em uma tentativa de esquivar-se desse efeito da Morte de Deus, que é a finitude do homem, por meio da fé na redenção pela razão científico-tecnológica, em 2001: uma odisseia no espaço esse traço patético do sujeito moderno inscreve-se em uma narrativa trágica, a qual oferece outro modo de operar com o mal estar da Modernidade. Diante dessa obra, que parece resistir à injunção cultural de paixão pelo autômato, nos perguntamos se outros filmes de ficção científica trabalham de forma análoga este modo do sujeito moderno defenderse da finitude. Em Blade runner (1982), de Ridley Scott, encontramos outro testemunho da arte como sofisticada forma de pensamento. Nessa narrativa distópica, que problematiza nosso conceito de humano, os androides encarnam as grandes angústias suscitadas pela Morte de Deus: a da origem e a da finitude. Nesse sentido, a identificação do espectador com os protagonistas do filme de Ridley Scott permite ir além do homem, entendido no sentido nietzschiano, 
isto é, como um sujeito para quem a finitude é insuportável. Se, em 2001, a música - Assim falou Zaratustra, de Richard Strauss - opera como um disparador da análise, em Blade runner a trilha sonora de Vangelis consiste em uma espécie de umbigo do filme, isto é, no ponto em que a obra de Ridley Scott tangencia o impossível da interpretação (Freud, 1900 / 1986a).

$\mathrm{Na}$ construção deste trabalho, a análise fílmica, tal como instaurada por Bellour (1979 / 2000) e teorizada por Aumont e Marie (2009) e Vanoye e Goliot-Lété (2009), consiste em importante ferramenta metodológica. $\mathrm{E}$ isso porque entendemos que a escuta psicanalítica de uma obra visual, como Freud (1914 / 1986c) realiza em O Moisés de Michelangelo, não pode prescindir de operar no registro próprio da linguagem em questão - no nosso caso, a linguagem cinematográfica. Na medida em que assumimos que a paixão pelo autômato, como disposição fundamental do sujeito moderno, pressupõe a fé cega na razão científica, adotamos algo do estilo trágico nietzschiano em nossa escrita. $E$ isso porque tal estilo resiste ao imperativo racionalista, lançando mão da expressão artística para alcançar o que escapa à razão, mas ainda assim faz pensar. Em outras palavras, nossa crítica da soberania da razão procura não cair em uma armadilha desse sistema de pensamento, que consiste em contrapor racionalidade objetiva (domínio da filosofia e da ciência) e criatividade subjetiva (domínio das artes). Tal enlace entre trabalho conceitual e criação artística parece-nos pertinente à pesquisa psicanalítica.

\section{A paixão pelo autômato}

A partir de nossa condição de psicanalistas que procuram escutar as produções da cultura, propomos o conceito paixão pelo autômato, a fim de apontar algo do pathos de nosso tempo. No entanto, não adotamos a equivalência entre pathos e doença, consagrada pelo saber médico moderno. Inspirados em $O$ que é pathos?, de Franciso Martins - artigo que realça a polissemia desse conceito -, articulamos duas outras concepções de pathos, a fim de operar nossas análises. Em Heidegger, "[...] o pathos estaria antes ligado a uma dis-posição (Stimmung) que antecede o conhecer e o querer" (Martins, 1999, p. 68). Trata-se de uma disposição afetiva fundamental, que atravessa o espírito de uma época. Em Kant, o conceito pathos alude à alienação de um sujeito a paixões poderosas. Nessa perspectiva, pensamos a paixão pelo autômato como uma disposição afetiva originária de nosso tempo, a qual todos estamos, em alguma medida, assujeitados.

Porém, que disposição é esta, a qual denominamos paixão pelo autômato? Em As palavras e as coisas, Foucault (1966 / 2002) 
observa que o sistema de pensamento instaurado pela dúvida cartesiana, no início do século XVII, sustenta-se na certeza da existência de Deus. Por esse motivo, em tal episteme o saber tende a desdobrar-se em totalidades acabadas e seu sujeito do conhecimento é ilimitado. No que concerne a seu regime de signos, o discurso consiste na rede transparente em que as palavras e as coisas enlaçam-se, sem fratura ou desencontro, pelos liames da representação.

Em contrapartida, o sistema de pensamento inaugurado pelas Luzes, no fim do século XVIII, é atravessado pelo problema da finitude. Por um lado, seu sujeito do conhecimento só pode pensar se tocado pelo sensível. Por outro, a historicidade é a marca principal de seus objetos empíricos. No que diz respeito a seu regime de signos, as palavras divorciam-se das coisas. Nessa perspectiva epistemológica, o homem ocupa um lugar privilegiado. Ele é, simultaneamente, sujeito e objeto do conhecimento. Na passagem da episteme clássica para a moderna, o sujeito ocidental desperta do sono dogmático, para imediatamente mergulhar no sono antropológico. Em tal crítica ao sistema de pensamento da Modernidade, o operador mais importante é o conceito nietzschiano Morte de Deus.

Assim falou Zaratustra, de Nietzsche, é um canto trágico, uma experimentação operada nos limites da razão, um singular encontro entre filosofia e poesia (Machado, 1997). Zaratustra é o profeta que desce a montanha para disseminar sua sabedoria entre os homens, mas se transfigura em quem deseja repetir as dores e delícias de ser o que é: "querer a eternização do instante vivido, pela afirmação de seu eterno retorno, é amar a vida com o máximo de intensidade" ( $p$. 142). Se, inicialmente, descer a montanha envolve elevar o espírito, em um movimento rumo à transcendência, ao longo de um percurso trágico torna-se encontro com a imanência da vida. Nessa perspectiva, a Morte de Deus alude à superação da distinção platônica entre aparência e essência. Diz Zaratustra:

Em outros tempos, blasfemar contra Deus era a maior das blasfêmias, mas Deus morreu e com Ele morreram esses blasfemadores. De agora em diante, o crime mais atroz é blasfemar contra a terra e ter em maior conta as entranhas do impenetrável do que o sentido da terra (Nietzsche, 1883 / 2005, p. 12).

Porém, a Morte de Deus também se refere ao triunfo do racionalismo humanista. Nesse sentido, o homem é o que tem de ser ultrapassado: "eu Ihes anuncio o Super-homem. O homem só existe para ser superado. O que fizeram para superá-lo?" (p. 11).

Porque Deus está morto, na episteme moderna o sujeito do conhecimento é limitado, os objetos empíricos são transitórios e as 
palavras fracassam em representar as coisas. Entretanto, Foucault (1966 / 2002) põe em relevo um ponto cego desse sistema de pensamento. $O$ homem, sujeito do conhecimento, é pensado a partir do homem, objeto das ciências humanas, as quais têm no homem, sujeito do conhecimento, seu a priori. O Homem: sujeito absoluto da Modernidade. Mediante esse vício de origem epistêmico, a razão científica elide seus limites e o sujeito moderno desmente a finitude que Ihe é constitutiva. Em tal solo cultural, o autômato consiste em um ideal. Por meio dele, o sujeito moderno visa driblar a finitude e aceder a um gozo ilimitado.

A Morte de Deus é condição de possibilidade do aparecimento da psicanálise. Ela consiste no a priori histórico da remissão das palavras a outras palavras, em busca de um objeto desde sempre perdido. No entanto, o desaparecimento de um referente absoluto também é objeto do discurso psicanalítico (Birman, 2005). Em Totem e tabu (Freud, 1913 / 1986b), não é o pai da horda primitiva que se depreende do mito cristão. É a Morte de Deus - o grande gozador do sujeito moderno - o tema crucial do mito trágico freudiano. Em $O$ futuro de uma ilusão, Freud (1927 / 1986h, p. 52) diagnostica a Morte de Deus e, em sintonia com a filosofia das Luzes, aposta na força da razão: "a voz do intelecto é suave, mas não descansa até ser escutada". Em Mal-estar na civilização (Freud, 1930 / 1986i), o fulcro da reflexão é o desamparo constitutivo do sujeito moderno, efeito da falta de suporte ontológico transcendente, e a impossibilidade do racionalismo iluminista contornar o mal-estar que the decorre. Se a paixão pelo autômato consiste em uma tentativa de desfazer os efeitos da Morte de Deus, por meio da fé na racionalidade científica sustentada em um sujeito transcendente, a psicanálise, saber que concerne a um sujeito atravessado pela finitude, opera como um contradiscurso. Ela se incumbe de indicar que o rei está nu.

\section{0 avesso da paixão}

$\mathrm{Na}$ escuridão dos primórdios, ao som de Assim falou Zaratustra, de Richard Strauss, o Sol sai de trás da Lua, lançando seus raios sobre a Terra. Em uma série de planos curtos e distantes, quase fotográficos, o alvorecer no deserto desdobra-se em outra série, em que planos mais longos e próximos revelam a árdua luta pela vida dos hominídeos. De repente, um grande monólito negro aparece. Alvoroço. Um plano subjetivo - a câmera assume a perspectiva do líder do bando - mostra o brilho do Sol rompendo o contorno da rocha. Enquadrado de corpo inteiro no centro do plano, o hominídeo olha ossos espalhados, pensativo. O poema sinfônico inspirado no célebre livro de Nietzsche explode. É a aurora da humanidade. 2001: uma odisseia no espaço (1968), de Stanley Kubrick, não apenas 
define o imaginário das viagens espaciais. Ele retoma o tema nietzschiano da Morte de Deus.

Em 1968 - ano do lançamento de 2001 e ano anterior ao pouso da Apollo 11 na Lua -, também é publicado Eram os deuses astronautas?, de Erich von Däniken (2011). Neste livro, postula-se que a inteligência humana é efeito do contato com extraterrestres, aos quais as civilizações antigas adorariam como divindades. No contexto das viagens espaciais, a construção de mitos de origem, a fim de reparar a falta de suporte ontológico transcendente do sujeito moderno, parece voltar-se para o espaço sideral. Entretanto, o best seller de von Däniken difere do clássico de Kubrick em um ponto crucial. Ele tem pretensão de cientificidade. Em contrapartida, embora cientificamente informado 2001 é um poema visual e musical. A despeito de sua temporalidade linear, pontuada por uma elipse de milhões de anos e outra de dezoito meses, sua narrativa, lenta e com pouco diálogo, é aberta, isto é, repleta de pontos que permanecem nebulosos. E nisso ela também se diferencia de 2001: uma odisseia no espaço, livro de Arthur C. Clarke (1968 / 2013), muito mais descritivo e explicativo.

A aposta deste trabalho é a de que o estilo de 2001 - o filme - é trágico, no sentido nietzschiano. De acordo com Machado (1997), em O nascimento da tragédia a crítica de Nietzsche ao imperativo racionalista é feita com as armas deste sistema de pensamento. É em Assim falou Zaratustra que se instaura uma filosofia trágica. Para Nietzsche, a dialética socrática sufoca as artes trágicas ao excluir do teatro grego o ditirambo dionisíaco - canto coral que realça o caráter passional da narrativa -, em favor de uma representação conceitual. Na Modernidade, esse expurgo do pathos - compreendido como isso que escapa à razão, mas incita o pensamento -, pelo método cartesiano, é condição da objetividade científica. É precisamente nesse sentido que a filosofia nietzschiana, assim como a psicanálise, contrapõe-se ao racionalismo e reintroduz o trágico no pensamento. Em 2001, turva-se a fronteira entre arte e filosofia. O filme de Kubrick consiste em um jorro de signos visuais e sonoros, que resistem a serem encerrados em uma significação. Ele não se dá a compreender, mas faz pensar.

No começo de Assim falou Zaratustra, de Nietzsche (1883 / 2005), o profeta sai de sua caverna e dialoga com o Sol. Machado (1997) sugere tratar-se de uma alusão ao mito platônico da caverna, o que faz de Zaratustra, antes de sua transfiguração dionisíaca, um herói apolíneo. Em 2001, há um signo que se repete, sempre associado ao monólito: o Sol saindo de trás de outro astro. Isso ocorre na sequência inicial, no final do segmento lunar e na abertura da parte intitulada "Júpiter e além do infinito". Nessas ocasiões, a coloração do Sol é semelhante à do olho de HAL, computador de última geração que suscita a paixão pelo autômato. Imagens do alvorecer, da 
aurora, do despertar - presentes no livro de Nietzsche, na música de Strauss e no filme de Kubrick? Metáfora do Esclarecimento? Os três primeiros minutos indicam que 2001 não veio para clarear, mas para deixar obscuro.

Talvez seja possível afirmar que os protagonistas de 2001 são o monólito e HAL. E não é difícil apontar o que os enlaça. O monólito é o pai do homem. HAL, sua suprema criação. Nessa linhagem, algo inevitavelmente vacila. Se, em 2001, constrói-se um mito de origem, nele o anseio de reencontrar o criador - na Lua, em Júpiter, ou além do infinito - não tem outro efeito senão o de relançar a narrativa. $O$ pai primordial é simbólico. O monólito é condição de possibilidade do deslizamento dos significantes fílmicos, não fonte de significação. Além disso, a humanização de HAL é indicada não apenas por sua inteligência e sentimentos. Inúmeros planos subjetivos the são concedidos. Ele é a imagem e semelhança do homem. Portanto, não se equivoca ao atribuir seu erro à falha humana. Em 2001, a paixão pelo autômato revela-se pelo avesso. Após HAL ser descerebrado, David (Keir Dullea) embarca em uma viagem psicodélica que, em sintonia com o momento (contra)cultural do final dos anos 1960, promove a ultrapassagem do regime epistêmico em que HAL é concebido.

O segmento final de 2001 é particularmente enigmático. Contudo, a análise de seu dispositivo narrativo permite formular uma interpretação. Simplificando, essa é sua estrutura: planos vistos desde a perspectiva de um narrador onisciente, que mostram os objetos no interior da casa e David, e planos subjetivos, em que David vê esses objetos e a si próprio, mais velho. Isso ocorre três vezes. Em todas, o ponto de vista desloca-se para a versão mais velha do personagem, que prossegue a narrativa. Em seu leito de morte, David vê o monólito. Da perspectiva deste, vemos um feto sobre a cama, no lugar de David. Close no feto que, em flagrante transgressão ao código narrativo clássico, olha para o espectador. Fomos capturados no jogo de olhares que relança esse discurso fílmico para além do infinito.

Assim como tantos outros filmes de ficção científica, 2001: uma odisseia no espaço opera com o fascínio que o autômato exerce sobre nós. Além disso, e diferentemente de muitas outras películas do gênero, ele articula esse tema ao anseio por uma filiação transcendente, que subjaz à paixão pelo autômato. No entanto, ao abordar essa inclinação das subjetividades modernas de um modo trágico, 2001 a desloca do registro racionalista em que ela floresce. $\mathrm{E}$, ao enlaçar o espectador em sua trama narrativa, o filme de Kubrick nos oferece uma forma de lidar com o mal estar da Modernidade, que não implica a denegação da Morte de Deus. 


\section{Paixão narcísica}

Los Angeles, novembro de 2019. Refletido em um belo olho azul, vemos um mundo consumir-se em explosões. $O$ ambiente noturno, chuvoso e esfumaçado, ruas superpovoadas e prédios abandonados, um enquadramento fechado, que beira o claustrofóbico, e uma iluminação tênue e difusa indicam ao espectador que o avanço tecnológico pode coexistir com uma perspectiva sombria do futuro. Quem quer viver nessa sociedade? A colonização interplanetária sustenta-se no trabalho escravo de androides, seres biomecânicos virtualmente idênticos aos humanos produzidos pela engenharia genética. Revoltados com sua condição, um grupo de replicantes como são denominados os androides Nexus 6, de última geração retorna à Terra, a fim de encontrar seu criador. "Qual o problema?", pergunta Eldon Tyrell (Joe Turkel). "Morte", diz Roy Batty (Rutger Hauer).

Blade runner (1982), de Ridley Scott, é uma distopia. Nele, androides padecem de uma estranha obsessão. Eles almejam tornar-se a imagem e semelhança do homem. Não apenas são atormentados pelo problema da finitude. Os replicantes cultivam laços fraternais, que Leon Kowalski (Brion James) faz questão de registrar em fotografias. Rachael (Sean Young) vai além. Ignorante de sua condição, ela cultiva laços de filiação. Em suas memórias implantadas - e quais não são? -, desdobra-se uma sinistra novela familiar. Sua fantasia primordial - os filhotes de aranha que devoram a mãe parece indicar o motivo da proibição dos androides voltarem à Terra: o temor do criador de ser destruído pela criatura.

No entanto, Blade runner não se restringe a humanizar androides. Inspirado no livro Androides sonham com ovelhas elétricas?, de Philip K. Dick (1968 / 2014), o filme põe em suspenso nosso conceito de humano. Rick Deckard (Harrison Ford), o caçador de androides, tem no policial Gaff (Edward Olmos) uma espécie de alter ego. Quando o delegado Bryant (Emmet Walsh) afirma: "se você não é tira, é gentinha", Gaff faz o origami de uma galinha (chicken, em inglês, designa galinha, mas também alude a covarde, marica). No momento em que Deckard prepara-se para fugir com Rachael, outro origami evoca o instante em que o protagonista, sentado ao piano junto às fotografias que compõem suas lembranças de infância, vê um unicórnio em devaneio. Ridley Scott parece parafrasear Philip K. Dick: androides sonham com seres mitológicos?

A incerteza acerca das fronteiras entre o humano e o androide, que permeia o filme, também se apoia em um elemento formal. Blade runner tem uma produção visual primorosa. Ainda que sua estética sombria mantenha turvado o olhar do espectador, ela incita a ver. Ao longo da narrativa, um signo repete-se: o olho. Ele está presente na cena de abertura, é por meio do reflexo pupilar que o teste Voight- 
Kampff reconhece um androide, o laboratório de engenharia genética invadido por Roy e Leon fabrica olhos e é furando os olhos de Tyrell que Roy - tal como um Édipo às avessas - mata seu criador. Em seu discurso de morte, Roy Batty, em um close que realça seu belo olho azul, enuncia: "tenho visto coisas nas quais vocês não acreditariam". É este olhar primordial que orienta nossa visão do filme? Se essa hipótese é coerente, temos que admitir que Blade runner é narrado da perspectiva de um androide.

Em Blade runner, o androide é o outro do homem, seu duplo estranhamente familiar (Freud, 1919 / 1986g). Se, dos primórdios da sétima arte à contemporaneidade, o autômato tende a encarnar os anseios de infinitude do sujeito moderno, na película de Ridley Scott ele consiste em um sinistro mensageiro da finitude do homem. Por esse motivo, os investidores do filme, que conquistaram o direito ao corte final em função do prazo e orçamento extrapolados, alteraram a versão do diretor, considerada inacessível ao grande público - ou, depreciativamente, filme de arte. Na versão lançada em 1982, a cena do devaneio com o unicórnio, que insinua a possibilidade de Deckard também ser um replicante, é expurgada. Além disso, é incluído um happy end. Deckard e Rachael voam por vales verdes e ensolarados, enquanto o protagonista nos informa que sua amante não tem data de término. Sobretudo, Deckard é replicado em um narrador em voz over, que preenche as lacunas de sentido e elimina qualquer ambiguidade no texto fílmico. Mediante esse procedimento, os investidores pretenderam exorcizar o que há de unheimlich inquietante, perturbador, avesso ao cinema comercial - em Blade runner, precisamente o que fez dele um cult movie.

Em Blade runner: entre o passado e o futuro, o sociólogo Paulo Menezes (1999) propõe uma análise que privilegia as articulações entre tempo e memória. O problema do tempo é introduzido pela ordem social vigente, na qual avanços tecnológicos coexistem com uma pletora de signos de decadência, assim como com a persistência de uma rígida segmentação. Nessa sociedade distópica, a elite coloniza outros planetas, androides são escravos e permanecem na Terra apenas os que, por diversos motivos, estão impossibilitados de migrar. É no momento em que um grupo de androides põe em questão sua condição e irrompe em um espaço social que não lhe é destinado, que tem início a narrativa. Porém, é sobretudo a partir das fotografias, que pululam em Blade runner, que Menezes pensa 0 enlace entre passado e futuro. De acordo com o autor, as fotos de Leon consistem em um modo dos androides introduzirem uma diferença no tempo, isto é, de escaparem à escravidão a um eterno presente. A fotografia de Rachael enraíza ainda mais longe suas memórias; ela alude à origem. Na perspectiva de Menezes, o que os replicantes almejam é uma temporalidade humana - memórias -, que lhes proporcione um fundamento ontológico. 
Em Blade runner, a paixão pelo autômato é narcísica (Freud, 1914 / 1986d). O filme incita o espectador a identificar-se com os androides. Nos outdoors eletrônicos, vemos mulheres orientais sorridentes ingerindo uma pílula. Alusão a outra distopia - Admirável mundo novo, de Aldous Huxley (1932 / 2001)? Em uma sociedade em que o alto nível de desenvolvimento tecnológico apaga as marcas da singularidade, o androide é, nas palavras de Tyrell, "mais humano que o humano". Em Blade runner, os replicantes consistem nos portadores das grandes angústias decorrentes da Morte de Deus: a da origem e a da finitude. Por esse motivo, o criador - Tyrell - não pode resolver o problema da criatura: Roy. Ele é atravessado pelo mesmo limite. Além disso, o filme toca em um ponto crucial: nossa origem é ficcional. Dito de outro modo, nossas memórias são implantadas pelos discursos que narram quem somos. São essas narrativas ficcionais que nos conferem alguma consistência ontológica. Paradoxalmente, em Blade runner a identificação do espectador com o androide oferece a possibilidade de ultrapassagem dessa inclinação do sujeito moderno, que é a paixão pelo autômato.

A análise de Blade runner remete-nos de volta ao problema do humano. Em Assim falou Zaratustra, Nietzsche (1883 / 2005) sugere que é preciso ir além do homem, pois o homem é um animal doente, incapaz de destacar-se do rebanho e afirmar a vida em seu enlace com a morte. Em As palavras e as coisas (Foucault, 1966 / 2002), o homem é um duplo empírico-transcendental, isto é, simultaneamente sujeito e objeto do conhecimento, unificado em um sujeito absoluto. $\mathrm{Na}$ episteme moderna, "[...] não se pode mais pensar senão no vazio do homem desaparecido" (p. 473). Em psicanálise, o homem é um ser atormentado por três feridas narcísicas: a teoria heliocêntrica de Copérnico, que postula que a Terra não é o centro do universo, a teoria evolucionista de Darwin, que afirma que a espécie humana descende de outros animais, e a teoria psicanalítica, que sustenta que "o eu não é o senhor em sua própria casa [grifo do autor]" (Freud, 1917 / 1986f, p. 133). Na Modernidade, o homem erige-se em sujeito transcendente, a fim de esquivar-se dos efeitos da Morte de Deus.

É nesse caldo de cultura que floresce a paixão pelo autômato. Trespassado pela finitude, o sujeito moderno desloca sua fé na eternidade para a razão científico-tecnológica. Inúmeras produções culturais testemunham esse traço singular da Modernidade. Entretanto, Blade runner é diferente. Em seu confronto final com Deckard, Roy - tal como um profeta do eterno retorno - relança a vida no momento da própria morte. Esse mútuo pertencimento entre vida e morte é assinalado por Freud (1916 / 1986e, p. 309-10), em A transitoriedade: 
O valor da transitoriedade é o da escassez no tempo. A restrição na possibilidade de gozo o torna mais apreciável. [...] No que concerne à beleza da natureza, a cada destruição pelo inverno ela volta no ano seguinte e esse retorno pode definir-se como eterno em proporção ao lapso que dura nossa vida. A formosura do corpo e do rosto humano vemos desaparecer para sempre dentro de nossa própria vida, mas essa brevidade agrega a seus encantos um novo. Se há uma flor que se abre uma única noite, não por isso sua florescência nos parece menos esplêndida.

Manter-se desejante diante do incontornável da morte. Não é este um ponto de contato entre o super-homem nietzschiano e o sujeito da psicanálise?

\section{Considerações finais}

Em 2001: uma odisseia no espaço, a paixão pelo autômato padece de excesso de identificação. HAL é demasiado humano. Em Blade runner, o fascínio pelo autômato implica a possibilidade de ir além do homem. Nesses dois clássicos da ficção científica, o cinema opera de modo a possibilitar ao espectador resistir à alienação a essa disposição afetiva fundamental da Modernidade, que é a paixão pelo autômato. Se a Morte de Deus introduz um desamparo primordial na subjetividade - tema central de Mal estar na civilização, de Freud -, a criação artística oferece outro modo de enfrentar a finitude, que não sua denegação racionalista, implicada na paixão pelo autômato.

\section{Referências}

Aumont, J. \& Marie, M. (2009). A análise do filme (M. Félix, Trad.). Lisboa: Texto e Grafia.

Bellour, R. (2000). The analysis of film (B. Brewster \& M. Quaintance, Trads.). Bloomington: Indiana University Press. (Original publicado em 1979)

Birman, J. (2005). Mal-estar na atualidade: a psicanálise e as novas formas de subjetivação ( $8 a$ ed.). Rio de Janeiro: Civilização Brasileira.

Clarke, A. (2013). 2001: uma odisseia no espaço (F. Fernandes, Trad.). São Paulo: Aleph. (Original publicado em 1968)

Däniken, E. (2011). Eram os deuses astronautas? (6a ed.). (E. G. Kalmus, Trad.). São Paulo: Melhoramentos. (Original publicado em 1968) 
Dick, P. (2014). Androides sonham com ovelhas elétricas? (R. Bressane, Trad.). São Paulo: Aleph. (Original publicado em 1968)

Foucault, M. (2002). As palavras e as coisas (8a ed.). (S. T. Muchail, Trad.). São Paulo: Martins Fontes. (Original publicado em 1966)

Freud, S. (1986a). La interpretación de los sueños. In: Sigmund Freud: obras completas (J. Etcheverry, Trad., Vols. 4 e 5, pp. 1-611). Buenos Aires: Amorrortu. (Original publicado em 1900)

Freud, S. (1986b). Tótem y tabú (J. Etcheverry, Trad., Vol. 13, pp. 1164). In: Sigmund Freud: obras completas. Buenos Aires: Amorrortu. (Original publicado em 1913)

Freud, S. (1986c). El Moisés de Miguel Angel (J. Etcheverry, Trad., Vol. 13, pp. 213-242). In: Sigmund Freud: obras completas. Buenos Aires: Amorrortu. (Original publicado em 1914)

Freud, S. (1986d). Introducción del narcisismo (J. Etcheverry, Trad., Vol. 14, pp. 65-98). In: Sigmund Freud: obras completas. Buenos Aires: Amorrortu. (Original publicado em 1914)

Freud, S. (1986e). La transitoriedad (J. Etcheverry, Trad., Vol. 14, pp. 305-311). In: Sigmund Freud: obras completas. Buenos Aires: Amorrortu. (Original publicado em 1916)

Freud, S. (1986f). Una dificultad del psicoanálisis (J. Etcheverry, Trad., Vol. 17, pp. 125-135). In: Sigmund Freud: obras completas. Buenos Aires: Amorrortu. (Original publicado em 1917)

Freud, S. (1986g). Lo ominoso (J. Etcheverry, Trad., Vol. 17, pp. 215-251). In: Sigmund Freud: obras completas. Buenos Aires: Amorrortu. (Original publicado em 1919)

Freud, S. (1986h). El porvenir de una ilusión (J. Etcheverry, Trad., Vol. 21, pp. 1-55). In: Sigmund Freud: obras completas. Buenos Aires: Amorrortu. (Original publicado em 1927)

Freud, S. (1986i). El malestar en la cultura (J. Etcheverry, Trad., Vol. 21, pp. 57-140). In: Sigmund Freud: obras completas. Buenos Aires: Amorrortu. (Original publicado em 1930)

Huxley, A. (2001). Admirável mundo novo (2a ed.). (L. Vallandro \& V. Oliveira, Trads.). Porto Alegre: Globo. (Original publicado em 1932)

Kubrick, S. (2002). 2001: uma odisseia no espaço. São Paulo: Warner Home Vídeo. DVD (148 min).

Machado, R. (1997). Zaratustra: tragédia nietzschiana (2a ed.). Rio de Janeiro: Jorge Zahar.

Martins, F. (1999). O que é pathos? Revista latinoamericana de psicopatologia fundamental, 2(4), 62-80.

Menezes, P. (1999). Blade runner: entre o passado e o futuro. Tempo social, 11(1), 137-166.

Nietzsche, F. (2005). Assim falou Zaratustra (M. Silva, Trad.). São Paulo: Rideel. (Original publicado em 1883) 
Scott, R. (2007). Blade runner. São Paulo: Warner Home Vídeo. DVD (117 $\mathrm{min})$.

Vanoye, F. \& Goliot-Lété, A. (2009). Ensaio sobre a análise fílmica (6a ed.). (M. Appenzeller, Trad.). Campinas: Papirus.

\section{Endereço para correspondencia}

\section{Amadeu de Oliveira Weinmann}

Universidade Federal do Rio Grande do Sul - UFRGS

Av. Montenegro, 186/602, CEP 90460-160, Porto Alegre - RS, Brasil

Endereço eletrônico: weinmann.amadeu@gmail.com

Roberto Henrique Amorim de Medeiros

Universidade Federal do Rio Grande do Sul - UFRGS

Rua São Manoel, 963, CEP 90620-110, Porto Alegre - RS, Brasil

Endereço eletrônico: robertoamorim80@hotmail.com

\section{Gustavo Caetano de Mattos Mano}

Universidade Federal do Rio Grande do Sul - UFRGS

Rua Francisco Ferrer, 441/501, CEP 90420-140, Porto Alegre - RS, Brasil

Endereço eletrônico: gustavo.mano@gmail.com

Recebido em: 25/10/2014

Reformulado em: 04/07/2016

Aceito em: 22/10/2016

\section{Notas}

* Professor Doutor do Departamento de Psicanálise e Psicopatologia do Instituto de Psicologia / UFRGS e do PPG em Psicanálise: Clínica e Cultura / UFRGS.

** Professor Doutor do Bacharelado em Saúde Coletiva e do PPG em Saúde Coletiva / UFRGS.

*** Psicólogo, Mestre em Psicologia Social e Institucional / UFRGS e Mestrando em Psicanálise: Clínica e Cultura / UFRGS. 